\title{
Characterization of tracheobronchomalacia in infants with hypophosphatasia
}

Raja Padidela ${ }^{1 *}$, Robert Yates ${ }^{2}$, Dan Benscoter ${ }^{3}$, Gary McPhail $^{3}$, Elaine Chan ${ }^{4}$, Jaya Nichani $^{1}$, M. Zulf Mughal ${ }^{1}$,

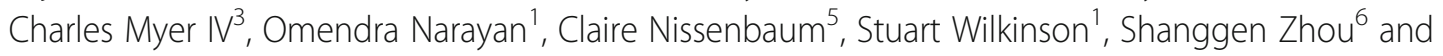
Howard M. Saal ${ }^{3}$

\section{Abstract}

Background: Perinatal and infantile hypophosphatasia (HPP) are associated with respiratory failure and respiratory complications. Effective management of such complications is of key clinical importance. In some infants with HPP, severe tracheobronchomalacia (TBM) contributes to respiratory difficulties. The objective of this study is to characterize the clinical features, investigations and management in these patients.

Methods: We report a case series of five infants with perinatal HPP, with confirmed TBM, who were treated with asfotase alfa and observed for 3-7 years. Additionally, we reviewed respiratory function data in a subgroup of patients with perinatal and infantile HPP included in the clinical trials of asfotase alfa, who required high-pressure respiratory support (positive end-expiratory pressure [PEEP] $\geq 6 \mathrm{~cm} \mathrm{H}_{2} \mathrm{O}$ and/or peak inspiratory pressure $\geq 18 \mathrm{~cm}$ $\mathrm{H}_{2} \mathrm{O}$ ) during the studies.

Results: The case series showed that TBM contributed significantly to respiratory morbidity, and prolonged respiratory support with high PEEP was required. However, TBM improved over time, allowing weaning of all patients from ventilator use. The review of clinical trial data included 20 patients and found a high degree of heterogeneity in PEEP requirements across the cohort; median PEEP was $8 \mathrm{~cm} \mathrm{H}_{2} \mathrm{O}$ at any time and some patients presented with high PEEP $\left(\geq 8 \mathrm{~cm} \mathrm{H}_{2} \mathrm{O}\right)$ over periods of more than 6 months.

Conclusion: In infants with HPP presenting with persistent respiratory complications, it is important to screen for TBM and initiate appropriate respiratory support and treatment with asfotase alfa at an early stage.

Trial registration: ClinicalTrials.gov numbers: NCT00744042, registered 27 August 2008; NCT01205152, registered 17 September 2010; NCT01176266, registered 29 July 2010.

Keywords: Hypophosphatasia, Tracheobronchomalacia, Respiratory failure, Respiratory support, Asfotase alfa

\footnotetext{
* Correspondence: Raja.Padidela@mft.nhs.uk

'Department of Paediatric Endocrinology, Royal Manchester Children's

Hospital and Faculty of Biology, Medicine and Health, University of Manchester, Manchester, UK

Full list of author information is available at the end of the article
}

(c) The Author(s). 2020 Open Access This article is licensed under a Creative Commons Attribution 4.0 International License, which permits use, sharing, adaptation, distribution and reproduction in any medium or format, as long as you give appropriate credit to the original author(s) and the source, provide a link to the Creative Commons licence, and indicate if changes were made. The images or other third party material in this article are included in the article's Creative Commons licence, unless indicated otherwise in a credit line to the material. If material is not included in the article's Creative Commons licence and your intended use is not permitted by statutory regulation or exceeds the permitted use, you will need to obtain permission directly from the copyright holder. To view a copy of this licence, visit http://creativecommons.org/licenses/by/4.0/ The Creative Commons Public Domain Dedication waiver (http://creativecommons.org/publicdomain/zero/1.0/) applies to the data made available in this article, unless otherwise stated in a credit line to the data. 


\section{Background}

Hypophosphatasia (HPP) is a rare, systemic, inherited, metabolic disease caused by deficient activity of the tissue non-specific isoenzyme of alkaline phosphatase (TNSA LP), resulting in the extracellular accumulation of its substrates - inorganic pyrophosphate (PPi), pyridoxal-5phosphate (PLP) and phosphoethanolamine (PEA) [1]. Perinatal HPP, which manifests in utero and is apparent at birth, is the most severe form of HPP, with severe skeletal hypomineralization characterized by respiratory failure due to gracile, thin, short ribs, small chest, hypoplastic lungs and vitamin B6-dependent seizures [2]. Infantile HPP, which is identified in patients before 6 months of age, is characterized by failure to thrive, hypercalcemia, short limbs, limb deformities with abnormal metaphyses, small thoraces with gracile, thin ribs, respiratory complications and vitamin B6-dependent seizures [2]. Patients with perinatal or infantile HPP and vitamin B6-dependent seizures have high morbidity and mortality in the first 5 years of life [3]; prior to the availability of asfotase alfa (Stren$\mathrm{siq}^{\circ}$ ), the only enzyme replacement therapy approved for the treatment of patients with perinatal/infantile- and juvenile-onset HPP, only $42 \%$ of infants with HPP survived their first year and only $27 \%$ survived to the age of 5 years, with death typically resulting from respiratory complications $[2,4-6]$. While asfotase alfa has been shown to improve survival in patients with perinatal and infantile HPP substantially [4], the characterization and management of respiratory complications in these patients remains key to their survival and to optimizing their treatment and clinical outcomes.

Multiple factors contribute to respiratory difficulties in infants with HPP. These include abnormal chest compliance arising from rachitic chest wall deformities and fractures, hypoplastic lungs, muscle weakness, episodic seizures, increased predisposition to infections secondary to TNSALP deficiency in leukocytes and, in some cases, severe tracheobronchomalacia (TBM) [4, 7-9]. Severe TBM is associated with an imminent risk of death from respiratory failure, complicated pulmonary infections and life-threatening cardiopulmonary arrests; infants with TBM therefore require intensive respiratory support from a broad group of specialists [10].

Even though TBM has been reported in patients with HPP [7-9], the clinical features, investigations and management in HPP have previously not been characterized. Here, we present a case series of five infants with perinatal HPP who had TBM contributing to severe respiratory compromise. To explore how common TBM may be amongst patients with HPP, we also reviewed respiratory function data (e.g. requirements for high positive end-expiratory pressure [PEEP] and/or peak inspiratory pressure [PIP]) in patients with perinatal and infantile HPP enrolled in the clinical trial programs for asfotase alfa.

\section{Patients and methods}

\section{Case series}

HPP diagnosis was confirmed in five infants by physical examination, skeletal survey (Fig. 1), serum biochemistry analysis (i.e. levels of the TNSALP substrates PPi, PLP and PEA) and genetic testing. Three patients were treated at the Royal Manchester Children's Hospital, UK, and two patients were treated at the Cincinnati Children's Hospital Medical Center, USA. Clinical suspicions of TBM in these five patients were raised following episodes of profound desaturations and bradycardia (especially on handling) and subsequent transient/episodic increases in ventilator requirements. Diagnosis of TBM was confirmed by direct laryngotracheobronchoscopy (DLTB) or flexible bronchoscopy. In this case series, respiratory support requirements were documented and defined as invasive ventilation (by continuous positive airway pressure [CPAP] or bilevel positive airway pressure support) via endotracheal tube or tracheostomy. Patients' demographic, genetic and clinical characteristics were summarized descriptively, as were their treatment and outcomes.
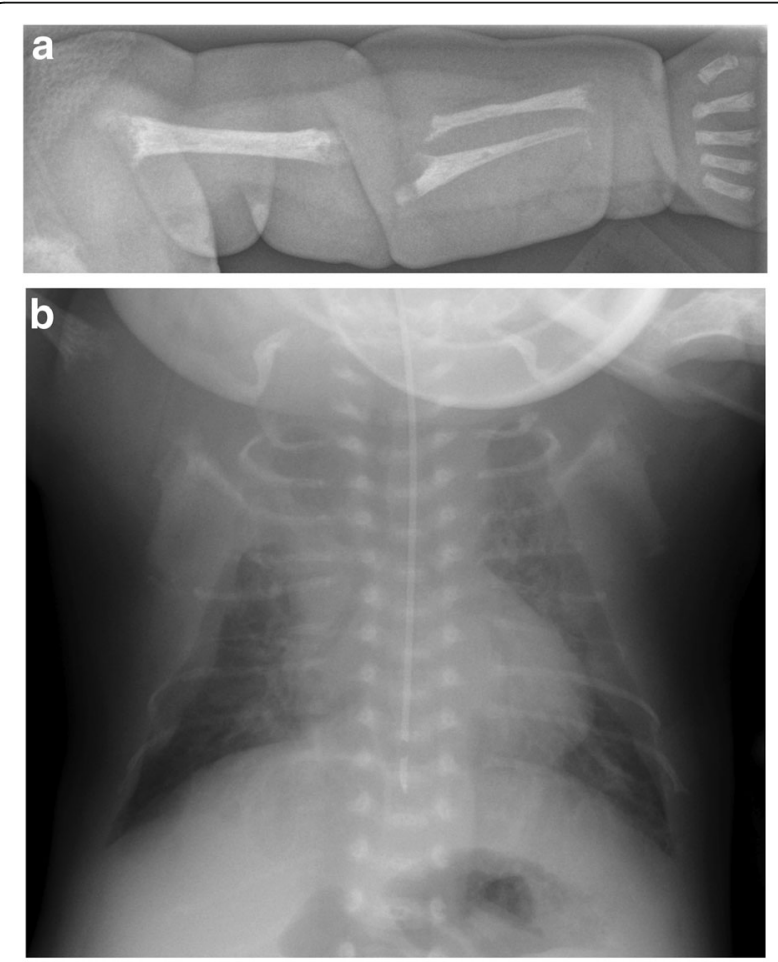

Fig. 1 Representative radiographs (Patient 1 at age 4 weeks). a Radiograph of the left upper limb showing severe rickets (bold arrows) and tongue-like metaphyseal lucencies (dotted arrows). b Radiograph of the chest showing gracile undermineralized ribs, a narrow thoracic cavity and small lung volumes 


\section{PEEP data from clinical trials}

PEEP values from two open-label, multicenter, phase 2, interventional trials of asfotase alfa in infants and young children with HPP (ENB-002-08 [NCT00744042]/ENB-003-08 [NCT01205152] and ENB-010-10 [NCT01176266]) were analyzed (excluding those patients who were included in the case series described above). These studies and the results for their pre-specified efficacy and safety outcome measures are described elsewhere [4, 11]. Briefly, 11 participants who were $\leq 36$ months old at initial enrollment and who had a documented diagnosis of severe HPP were recruited for ENB-002-08/ENB-003-08; for ENB-010-10, 69 participants aged $\leq 5$ years old, who had a documented diagnosis of HPP and onset of symptoms prior to 6 months of age, were recruited.

A subset of patients were identified who required any respiratory support, with PEEP $\geq 6 \mathrm{~cm} \mathrm{H}_{2} \mathrm{O}$ and/or PIP $\geq 18 \mathrm{~cm} \mathrm{H}_{2} \mathrm{O}$ (in line with the PEEP and PIP values measured in the patients with confirmed TBM included in the case series) at any time during the study, but who did not have a diagnosis of TBM. PEEP values from this subset of patients were examined across the course of the studies to evaluate how frequently high ventilator settings were required as well as to look at variations in the evolution of respiratory function over time, to gain insights on which infants with HPP with respiratory requirements should be screened for possible TBM. The Kendall rank correlation coefficient was used to measure ordinal associations between PEEP requirements (median and maximum) and the percentage of the duration of respiratory support for which PEEP $\geq 6 \mathrm{~cm} \mathrm{H}_{2} \mathrm{O}$ was required.

\section{Results \\ Case series}

Five infants (three females and two males) with HPP, all of whom experienced respiratory distress at birth and required respiratory support, had TBM confirmed at $\leq 5$ months of age. Their baseline demographic and clinical characteristics at birth and results of their laboratory analyses are presented in Tables 1 and 2, respectively. ALPL gene mutations were found in all five patients; two infants had compound heterozygous gene mutations and the other three had homozygous mutations. All mutations except the c.876_872delAGGGGACinsT mutation identified in Patient 3 have been reported previously $[12,13]$.

\section{Case report findings \\ Patient 1}

HPP medical history and management Patient 1 presented immediately after birth with poor feeding, significant hypotonia and respiratory distress. Antenatal scans showed shortening of the long bones and a skeletal survey revealed manifestations of HPP with severe rickets, thin undermineralized ribs, a small thoracic cavity and small lung volumes (Fig. 1). The patient was included in study ENB-010-10 and treatment with asfotase alfa was commenced at 1 month of age.

Table 1 Baseline demographic and clinical characteristics at birth in infants included in the case series

\begin{tabular}{|c|c|c|c|c|c|}
\hline \multirow[t]{2}{*}{ Characteristic } & \multicolumn{3}{|c|}{$\begin{array}{l}\text { Patients Who Received Asfotase Alfa as Part of the ENB- } \\
010-10 \text { Study }\end{array}$} & \multirow{2}{*}{$\begin{array}{l}\text { Patient Who Received Asfotase } \\
\text { Alfa Through Compassionate- } \\
\text { Use Program } \\
\text { Patient } 4\end{array}$} & \multirow{2}{*}{$\begin{array}{l}\text { Patient Who Received Asfotase } \\
\text { Alfa as Licensed Medication Post- } \\
\text { Authorization } \\
\text { Patient } 5\end{array}$} \\
\hline & Patient 1 & Patient 2 & Patient 3 & & \\
\hline Sex & Male & Male & Female & Female & Female \\
\hline Ethnicity & White Caucasian & $\begin{array}{l}\text { White } \\
\text { Caucasian }\end{array}$ & $\begin{array}{l}\text { White } \\
\text { Caucasian }\end{array}$ & Asian-Pakistani & White Caucasian \\
\hline Gestational age & Term & Term & $\begin{array}{l}35 \text { weeks, } \\
4 \text { days }\end{array}$ & 34 weeks & Term \\
\hline Birth weight & $2.89 \mathrm{~kg}$ & $3.46 \mathrm{~kg}$ & $3.06 \mathrm{~kg}$ & $1.69 \mathrm{~kg}$ & $3.46 \mathrm{~kg}$ \\
\hline $\begin{array}{l}\text { Post-birth } \\
\text { respiratory } \\
\text { support }\end{array}$ & $\begin{array}{l}\text { CPAP ventilation at birth; } \\
\text { intubation and ventilation } \\
\text { starting at } 4 \text { weeks }\end{array}$ & $\begin{array}{l}\text { Intubation } \\
\text { and } \\
\text { ventilation }\end{array}$ & $\begin{array}{l}\text { Intubation } \\
\text { and } \\
\text { ventilation }\end{array}$ & $\begin{array}{l}\text { Intubation and ventilation: } \\
\text { surfactant }\end{array}$ & Intubation and ventilation at birth \\
\hline $\begin{array}{l}\text { Presence of } \\
\text { skeletal } \\
\text { manifestations of } \\
\text { HPP }\end{array}$ & Yes & Yes & Yes & Yes & Yes \\
\hline $\begin{array}{l}\text { Presence of } \\
\text { hypotonia }\end{array}$ & Yes & Yes & Yes & Yes & Yes \\
\hline $\begin{array}{l}\text { Presence of } \\
\text { feeding difficulty }\end{array}$ & Yes & Yes & Yes & Yes & Yes \\
\hline
\end{tabular}


Table 2 Results of laboratory analyses conducted for infants included in the case series

\begin{tabular}{|c|c|c|c|c|c|}
\hline \multirow{2}{*}{$\begin{array}{l}\text { Laboratory } \\
\text { Measure }\end{array}$} & \multicolumn{3}{|c|}{ Patients Who Received Asfotase Alfa as Part of the ENB-010-10 Study } & \multirow{2}{*}{$\begin{array}{l}\text { Patient Who Received } \\
\text { Asfotase Alfa Through } \\
\text { Compassionate-Use } \\
\text { Program } \\
\text { Patient } 4\end{array}$} & \multirow{2}{*}{$\begin{array}{l}\text { Patient Who Received } \\
\text { Asfotase Alfa as } \\
\text { Licensed Medication } \\
\text { Post-Authorization } \\
\text { Patient } 5\end{array}$} \\
\hline & Patient 1 & Patient 2 & Patient 3 & & \\
\hline $\begin{array}{l}\text { Alkaline } \\
\text { phosphatase at } \\
\text { birth (normal } \\
\text { range: } 82-383 \text { ) }\end{array}$ & Undetectably low & $14 \mathrm{U} / \mathrm{L}$ & $18 \mathrm{U} / \mathrm{L}$ & Undetectably low & $<5 \mathrm{U} / \mathrm{L}$ \\
\hline $\begin{array}{l}\text { Calcium (normal } \\
\text { range: } 2.25- \\
2.74 \text { ) }\end{array}$ & $3.0 \mathrm{mmol} / \mathrm{L}$ at birth & $2.9 \mathrm{mmol} / \mathrm{L}$ at 4 weeks & $\begin{array}{l}1.3 \mathrm{mmol} / \mathrm{L} \text { (ionized, } \\
\text { normal range: } 0.85-1.45 \text { ) } \\
\text { at } 8 \text { days }\end{array}$ & $2.9 \mathrm{mmol} / \mathrm{L}$ at 4 weeks & $3.0 \mathrm{mmol} / \mathrm{L}$ at birth \\
\hline $\begin{array}{l}\text { Phosphorus } \\
\text { (normal range) }\end{array}$ & NA & $\begin{array}{l}4.3 \mathrm{mg} / \mathrm{dL}(2.5-4.5) \text { at } 4 \\
\text { weeks }\end{array}$ & $\begin{array}{l}6.8 \mathrm{mg} / \mathrm{dL}(2.5-4.5) \text { at } 8 \\
\text { days }\end{array}$ & $\begin{array}{l}2.4 \mathrm{mmol} / \mathrm{L}(1.8-2.3) \text { at } \\
4 \text { weeks }\end{array}$ & $\begin{array}{l}2.3 \mathrm{mmol} / \mathrm{L}(1.8-2.3) \text { at } \\
\text { birth }\end{array}$ \\
\hline $\begin{array}{l}\text { PLP (B6) (normal } \\
\text { range) }\end{array}$ & NA & $\begin{array}{l}>2000 \mathrm{ng} / \mathrm{mL}(11.8-68.3) \\
\text { at } 1 \text { day }\end{array}$ & $\begin{array}{l}\text { NA; PEA } 413 \mu \mathrm{mol} / \mathrm{L}(0- \\
300)\end{array}$ & $\begin{array}{l}4740 \mathrm{ng} / \mathrm{mL}(11.8-68.3) \\
\text { at } 4 \text { weeks }\end{array}$ & $3940 \mathrm{nmol} / \mathrm{L}(20-140)$ \\
\hline $\begin{array}{l}\text { PPi (normal } \\
\text { range: } 1.33- \\
5.71 \text { ) }\end{array}$ & $9.5 \mu \mathrm{mol} / \mathrm{L}$ at 4 weeks & $10.4 \mu \mathrm{mol} / \mathrm{L}$ at 5 weeks & $7.4 \mu \mathrm{mol} / \mathrm{L}$ at 7 weeks & $9.5 \mu \mathrm{mol} / \mathrm{L}$ at 4 weeks & NA \\
\hline ALPL mutation & $\begin{array}{l}\text { Homozygous: c.147 G > } \\
\text { A, (p.Gly491Arg) } \\
\text { secondary to } \\
\text { uniparental disomy [12] }\end{array}$ & $\begin{array}{l}\text { Compound heterozygous: } \\
\text { c.668 G > A (p.Arg223Gln) } \\
\text { and c.1171 C>T } \\
\text { (p.Arg391Cys) }\end{array}$ & $\begin{array}{l}\text { Compound heterozygous: } \\
\text { c.876- } \\
872 \text { delAGGGGACinsT and } \\
\text { c.650 T > C (p.Val217Ala) }\end{array}$ & $\begin{array}{l}\text { Homozygous: c.1336 } \\
\text { G > A (p.Ala466Thr) }\end{array}$ & $\begin{array}{l}\text { Homozygous: c.400_ } \\
\text { 401delinsCA, } \\
\text { (p.Thr134His) }\end{array}$ \\
\hline
\end{tabular}

NA Not available, PEA Phosphoethanolamine, PLP Pyridoxal-5-phosphate, PPi Inorganic pyrophosphate

Respiratory measures and mechanics The patient experienced progressive worsening of respiratory function and continued to have episodes of desaturations, requiring PEEP of $8 \mathrm{~cm} \mathrm{H}_{2} \mathrm{O}$. A DLTB performed at 2 months of age revealed severe laryngotracheobronchomalacia, which required PEEP of $12 \mathrm{~cm} \mathrm{H}_{2} \mathrm{O}$ to keep the airways patent, with positive pressure ventilation delivered through tracheostomy. Respiratory function subsequently improved, with reduction in PEEP to $6 \mathrm{~cm} \mathrm{H}_{2} \mathrm{O}$ at 9 months of age.

Follow-up At 1 year of age, ventilation was tapered and changed to CPAP via tracheostomy; chest radiograph showed significantly improved mineralization of the ribs and increased lung volume (Fig. 2). By 14 months of age the patient was self-ventilating in room air with complete clinical resolution of laryngotracheobronchomalacia.

\section{Patient 2}

HPP medical history and management Radiographs taken at 1 day of age revealed that Patient 2 had remarkably diminished ossification of the skull with almost no cranial calcification. He also had diminished ossification and height of vertebral bodies, and absent ossification of the humeral, radial and ulnar metaphyses with marked metaphyseal irregularity, fragmentation and fraying. His chest was small and the bones abnormal, with absent ossification of medial ribs and gracile appearance of the ribs.
The patient was included in study ENB-010-10, and treatment with asfotase alfa was initiated at 5 weeks of age.

Respiratory measures and mechanics At 1 month of age, the patient required PEEP of $8 \mathrm{~cm} \mathrm{H}_{2} \mathrm{O}$. From 6 weeks of age, continuous ventilator support was required with PEEP of up to $12 \mathrm{~cm} \mathrm{H}_{2} \mathrm{O}$. Diagnosis of TBM was

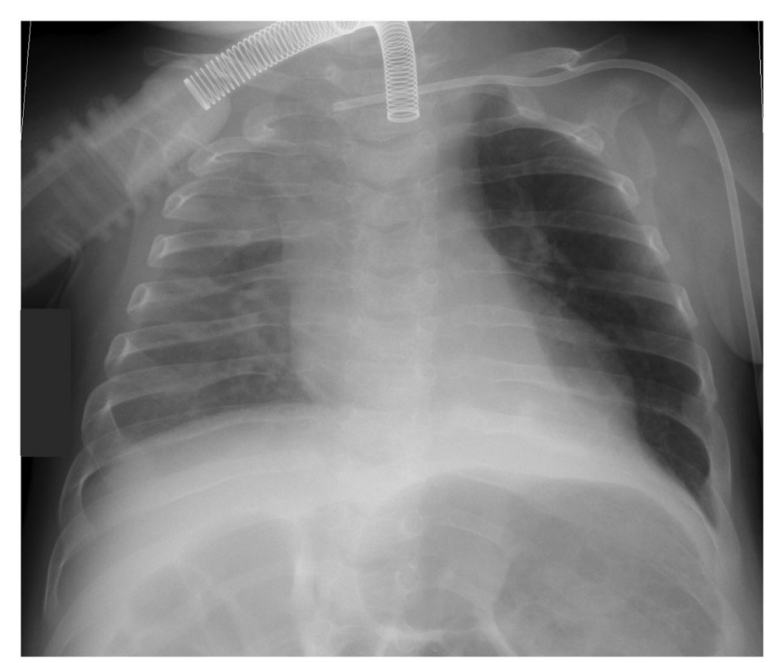

Fig. 2 Chest radiograph of Patient 1 after 11 months of treatment with asfotase alfa. Chest radiograph of Patient 1 at 1 year of age, after 11 months of treatment with asfotase alfa. The radiograph showed an improvement in the mineralization of the ribs and an increase in the volume of the thoracic cavity compared with that observed at age 4 weeks (see Fig. 1b) 
confirmed by tracheobronchoscopy at 5 months of age (Fig. 3).

Follow-up There was significant improvement at 12 months of age, with mild TBM and episodes of respiratory arrest resolved; PEEP of $10 \mathrm{~cm} \mathrm{H}_{2} \mathrm{O}$ was required. At 17 months of age, the lower airways appeared normal, with no appreciable dynamic collapse during breathing at rest; however, there was profound TBM when the patient was coughing or during forced exhalation, and PEEP of $10 \mathrm{~cm} \mathrm{H}_{2} \mathrm{O}$ was still required. At 5 years and 9 months of age, the patient was off the ventilator for $4 \mathrm{~h}$ three times per day, and discontinuation of daytime ventilation was planned for the following months. There were no serious setbacks, and, despite global developmental delays, language was improving and the patient was able to recognize most objects and animals.

\section{Patient 3}

HPP medical history and management Initial examination of Patient 3 found a very large anterior fontanelle, cranial molding, small chest with subcostal retractions and short, deformed extremities with bowing (equinovarus). Her feet were angulated and clubbed, with dimpling below the knees. X-rays showed severely decreased mineralization, diffuse osteopenia, poorly ossified ribs and irregularity of the right proximal humerus consistent with fracture. Additional radiographs documented bilateral humeral fractures. The patient was included in study ENB-010-10, and treatment with asfotase alfa was initiated at 1 month and 23 days of age.

Respiratory measures and mechanics At 1 month and 19 days of age, there was profound dynamic collapse of the trachea and bronchi during coughing or heavy breathing, even while intubated and receiving positive pressure. Despite increasing PEEP to $10 \mathrm{~cm} \mathrm{H}_{2} \mathrm{O}$, respiratory arrests with bradycardia requiring major intervention $\left(100 \%\right.$ fraction of inspired $\mathrm{O}_{2}$ delivered by positive pressure, and chest compressions for bradycardia) occurred on an almost weekly basis. At 5 months of age, there was profound bronchomalacia with complete collapse of the airway lumen on coughing or heavy breathing.

Follow-up The severe respiratory episodes decreased in frequency and at 12 months of age flexible bronchoscopy revealed moderate TBM, which, though considered significant, appeared to be improved from the previous evaluation at 6 months of age, with the PEEP requirement decreased to $9 \mathrm{~cm} \mathrm{H}_{2} \mathrm{O}$ from $12 \mathrm{~cm} \mathrm{H}_{2} \mathrm{O}$. At 18 months of age, there remained significant TBM, and PEEP of $12 \mathrm{~cm} \mathrm{H}_{2} \mathrm{O}$ was required. At 5 years and 5 months of age, the patient was off the ventilator during the daytime, with rapid and complete discontinuation of ventilation and microlaryngobronchoscopy planned. In addition, cognitive development was progressing and the patient was able to recognize all letters, numbers, animals and body parts. The patient was also able to stand unassisted for short periods.

\section{Patient 4}

HPP medical history and management Patient 4 was found to have dysmorphic features with short limbs, craniotabes and significant hypotonia, and her skeletal survey revealed characteristic features of HPP. Treatment with asfotase alfa was commenced at 1 month of age through a compassionate-use program.

Respiratory measures and mechanics Despite improvements in biochemistry results within 7 days of starting treatment with asfotase alfa, Patient 4 continued to have increased ventilator requirements (including PEEP of up to $6 \mathrm{~cm} \mathrm{H}_{2} \mathrm{O}$ ) with episodes of significant bradycardia and desaturations. At 3 months and 9 days of age, these culminated in an acute deterioration requiring chest compression and inotropes for cardiac arrest. The dose of asfotase alfa was then increased and within
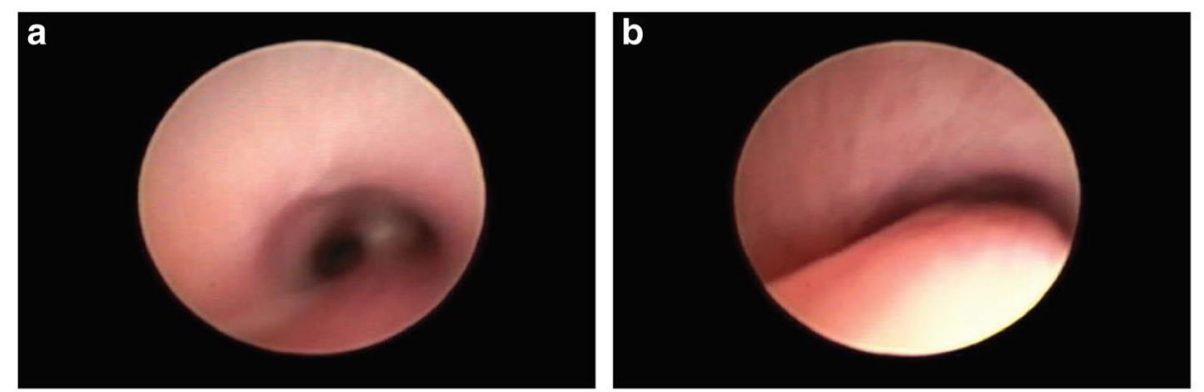

Fig. 3 Representative tracheobronchoscopy (Patient 2 at age 5 months). Representative images of the right mainstem bronchus during inspiration (a) and expiration (b) from Patient 2 
2 weeks she showed improvement. A DLTB performed at 5 months of age demonstrated significant laryngotracheobronchomalacia, with an opening pressure (PEEP) of $12 \mathrm{~cm} \mathrm{H}_{2} \mathrm{O}$.

Follow-up Respiratory function significantly improved with the increase in PEEP, and by 8 months of age PEEP was reduced to $9 \mathrm{~cm} \mathrm{H}_{2} \mathrm{O}$. At 11 months of age, a repeat DLTB showed complete resolution of laryngotracheobronchomalacia, and by 2 years of age the patient had been weaned off ventilation completely.

\section{Patient 5}

HPP medical history and management Patient 5 was diagnosed with HPP antenatally at 32 weeks of gestational age when a fetal ultrasound scan showed skeletal features suggestive of HPP. Her mother previously underwent a termination of a fetus that had HPP confirmed following genetic testing, and both parents were known to be heterozygous carriers for ALPL gene mutation. Treatment with asfotase alfa was initiated immediately after birth.

Respiratory measures and mechanics Patient 5 was intubated and ventilated at birth. Her ventilatory requirements increased at 3 months of age, with progressive increase in fraction of inspired oxygen from $21 \%$ to $50-60 \%$ and of PIP from 16 to $22 \mathrm{~cm} \mathrm{H}_{2} \mathrm{O}$ with episodic worsening during routine care and handling. A DLTB at 3 months showed TBM, which required PEEP of $12 \mathrm{~cm}$ $\mathrm{H}_{2} \mathrm{O}$ to keep the airway patent.

Follow-up High PEEP (up to $12 \mathrm{~cm} \mathrm{H}_{2} \mathrm{O}$ ) was required by Patient 5 until 6 months of age, when it was reduced to $6 \mathrm{~cm} \mathrm{H}_{2} \mathrm{O}$. Weaning from ventilation was then initiated and complete by 9 months of age. At 13 months of age, a repeat DLTB showed residual TBM, but this was not clinically significant as the patient no longer required ventilatory support.

In summary, all patients required tracheostomy for long-term ventilation with PEEP of up to $12 \mathrm{~cm} \mathrm{H}_{2} \mathrm{O}$ following commencement of respiratory support at birth. Images from one patient at age 5 months show the right mainstem bronchus during inspiration (Fig. 3a) and expiration (Fig. 3b) (the source video file is included in the supplemental materials). Normal anatomy and airway patency are evident during inspiration; on expiration, however, near-complete collapse of the right mainstem bronchus is seen.

All patients received ongoing treatment with asfotase alfa $6-15 \mathrm{mg} / \mathrm{kg} /$ week, starting at $0-7$ weeks of age. TBM was confirmed within 6 months of birth for all five patients and was suspected in one patient as early as 8 weeks after birth. All patients had frequent episodes of profound desaturations and bradycardia, and three experienced cardiorespiratory arrests. Treatment and outcomes are summarized for each patient in Table 3.

\section{PEEP data from clinical trials}

Among all infants who need ventilatory support, PEEP requirements and ventilation strategies are heavily influenced by the underlying cause of chronic respiratory failure. However, in our experience, infants without significant lung disease or TBM may typically require PEEP of $4-8 \mathrm{~cm} \mathrm{H}_{2} \mathrm{O}$. Of the 80 patients included in the asfotase alfa clinical trials, 39 required respiratory support at any time; 23 of these 39 (59\%) patients required high-pressure respiratory support (PEEP $\geq 6 \mathrm{~cm} \mathrm{H}_{2} \mathrm{O}$ and/or PIP $\geq 18 \mathrm{~cm} \mathrm{H}_{2} \mathrm{O}$ ) via any route, at any time (22 of these patients required respiratory support at baseline, and one patient did not have baseline respiratory support information). Three of these patients are included in the case series described above, and therefore not included in these additional analyses. Thus, results of an analysis of PEEP measurements (in line with the requirements of the case series patients) for 20 patients are presented here and in Supplemental Table 1. The median PEEP at any time was $8 \mathrm{~cm} \mathrm{H}_{2} \mathrm{O}$, with a highest PEEP of $20 \mathrm{~cm} \mathrm{H}_{2} \mathrm{O}$. The median number of days of highpressure respiratory support for these patients during the studies was 176 (1-1065; the median number of days on study for these patients was 912.5 [2-2724]), or $85.2 \%(9.3-100.0 \%)$ of the duration of respiratory support. Most of these 20 patients required high-pressure respiratory support across the entire period of their respiratory support. However, there was no correlation between the duration that those patients received ventilatory support and a PEEP requirement of $\geq 6 \mathrm{~cm}$ $\mathrm{H}_{2} \mathrm{O}$ (median PEEP $\mathrm{\tau}=.15, P=.44$; maximum PEEP $\mathrm{\tau}=$ $.09, P=.65)$. In this cohort, there were seven patients with even higher respiratory requirements for PEEP $(\geq 8$ $\mathrm{cm} \mathrm{H}_{2} \mathrm{O}$ ) and four patients with both PEEP $\geq 8 \mathrm{~cm} \mathrm{H}_{2} \mathrm{O}$ and $\mathrm{PIP} \geq 20 \mathrm{~cm} \mathrm{H}_{2} \mathrm{O}$ at any time. There was a high degree of heterogeneity in PEEP requirements across the cohort of included patients; however, six patients presented with consistently high PEEP values $\left(\geq 8 \mathrm{~cm} \mathrm{H}_{2} \mathrm{O}\right)$ over periods of more than 6 months.

\section{Discussion}

We have detailed the clinical course of TBM in five patients with perinatal-onset HPP; in our cohort, TBM contributed significantly to respiratory morbidity. More specifically, these patients required prolonged respiratory support with high PEEP in an intensive care unit setting and ongoing positive pressure to prevent collapse of airways. We typically increase PEEP in response to patient behaviors that cause us to suspect TBM. However, in 
Table 3 Overview of treatment and patient outcomes in infants included in the case series

\begin{tabular}{|c|c|c|c|c|c|}
\hline \multirow[t]{2}{*}{ Treatment } & \multicolumn{3}{|c|}{ Patients Who Received Asfotase Alfa as Part of the ENB-010-10 Study } & \multirow{2}{*}{$\begin{array}{l}\text { Patient Who } \\
\text { Received } \\
\text { Asfotase Alfa } \\
\text { Through } \\
\text { Compassionate- } \\
\text { Use Program } \\
\text { Patient } 4\end{array}$} & \multirow{2}{*}{$\begin{array}{l}\text { Patient Who Received } \\
\text { Asfotase Alfa as Licensed } \\
\text { Medication Post- } \\
\text { Authorization } \\
\text { Patient } 5\end{array}$} \\
\hline & Patient 1 & Patient 2 & Patient 3 & & \\
\hline $\begin{array}{l}\text { Asfotase } \\
\text { alfa } \\
\text { dosage, } \\
\text { mg/kg/ } \\
\text { week }\end{array}$ & $\begin{array}{l}1 \text { month: } 6 \\
3 \text { months: } 9 \\
\text { Current: } 7.5\end{array}$ & $\begin{array}{l}5 \text { weeks: } 6 \\
6 \text { months: } 7.8 \\
9 \text { months: } 7.5 \\
\text { Current: } 9\end{array}$ & $\begin{array}{l}7.5 \text { weeks: } 6 \\
\text { Current: } 12\end{array}$ & $\begin{array}{l}1 \text { month: } 6 \\
3.5 \text { months } \\
\text { (post-cardiac } \\
\text { arrest): } 15 \\
\text { Current: } 7.5\end{array}$ & $\begin{array}{l}\text { Birth: } 6 \\
2 \text { months: } 9 \\
3 \text { months: } 15 \\
\text { Current: } 7.5\end{array}$ \\
\hline $\begin{array}{l}\text { Surgical } \\
\text { treatments }\end{array}$ & $\begin{array}{l}5 \text { weeks: } \\
\text { tracheostomy }\end{array}$ & $\begin{array}{l}6 \text { weeks: tracheostomy } \\
4 \text { months: gastrostomy }\end{array}$ & $\begin{array}{l}7 \text { weeks: tracheostomy } \\
3 \text { months: gastrostomy }\end{array}$ & $\begin{array}{l}6 \text { weeks: } \\
\text { tracheostomy } \\
1 \text { year: } \\
\text { gastrostomy }\end{array}$ & $\begin{array}{l}3 \text { days: tracheostomy and } \\
\text { central venous access } \\
16 \text { months: left } \\
\text { ureteroscopy with laser } \\
\text { lithotripsy for renal stone } \\
\text { obstructing left ureter } \\
\text { causing left } \\
\text { hydronephrosis } \\
19 \text { months: closure of } \\
\text { tracheostomy } \\
2 \text { years: surgical correction } \\
\text { of craniosynostosis }\end{array}$ \\
\hline $\begin{array}{l}\text { Age at } \\
\text { TBM } \\
\text { diagnosis }\end{array}$ & 2 months & 5 months & 5 months (suspected at 8 weeks) & 5 months & 3 months \\
\hline $\begin{array}{l}\text { Current } \\
\text { age }\end{array}$ & $\begin{array}{l}5 \text { years, } 8 \\
\text { months }\end{array}$ & 5 years, 9 months & 5 years, 5 months & 7 years, 2 months & 3 years, 4 months \\
\hline $\begin{array}{l}\text { Long-term } \\
\text { follow-up } \\
\text { and } \\
\text { current } \\
\text { status }\end{array}$ & $\begin{array}{l}15 \text { months: } \\
\text { complete } \\
\text { clinical } \\
\text { resolution and } \\
\text { self-ventilating } \\
\text { in room air }\end{array}$ & $\begin{array}{l}17 \text { months: normal-appearing } \\
\text { lower airways, but profound } \\
\text { TBM when coughing or bearing } \\
\text { down; } \mathrm{BiPAP} \text { : PIP } 24 \mathrm{~cm} \mathrm{H}_{2} \mathrm{O} \text {, } \\
\text { PEEP } 10 \mathrm{~cm} \mathrm{H}_{2} \mathrm{O} \\
27 \text { months: remains on } \\
\text { ventilator; respiratory issues (viral } \\
\text { infections) requiring hospital } \\
\text { readmission; BiPAP: PIP } 22 \mathrm{~cm} \\
\mathrm{H}_{2} \mathrm{O}, \mathrm{PEEP} 8 \mathrm{~cm} \mathrm{H} \mathrm{H}_{2} \mathrm{O} \\
5 \text { years, } 9 \text { months: off ventilator } \\
\text { for } 4 \mathrm{~h} \text { three times daily; plan to } \\
\text { completely wean from daytime } \\
\text { ventilator by } 6 \text { years of age }\end{array}$ & $\begin{array}{l}18 \text { months: significant TBM } \\
\text { identified (severity difficult to } \\
\text { assess owing to well-positioned } \\
\text { custom tracheostomy tube in dis- } \\
\text { tal trachea); BiPAP: PIP } 26 \mathrm{~cm} \mathrm{H}_{2} \mathrm{O} \text {, } \\
\text { PEEP } 12 \mathrm{~cm} \mathrm{H}_{2} \mathrm{O} \\
23 \text { months: tracheostomy in situ } \\
\text { with ventilator support; } \mathrm{BiPAP} \text { : PIP } \\
25 \mathrm{~cm} \mathrm{H}_{2} \mathrm{O} \text {, PEEP } 12 \mathrm{~cm} \mathrm{H}_{2} \mathrm{O} \\
5 \text { years, } 5 \text { months: off ventilator for } \\
16-18 \mathrm{~h} \text { daily; plan to rapidly } \\
\text { completely discontinue ventilator } \\
\text { support in the coming months }\end{array}$ & $\begin{array}{l}2 \text { years: all } \\
\text { ventilator } \\
\text { support removed }\end{array}$ & $\begin{array}{l}9 \text { months: all ventilator } \\
\text { support removed }\end{array}$ \\
\hline
\end{tabular}

BiPAP Bilevel positive airway pressure, PEEP Positive end-expiratory pressure, PIP Positive inspiratory pressure, TBM Tracheobronchomalacia

many cases of severe TBM, the patient can overcome the distending pressure of even very high PEEP through coughing or the Valsalva maneuver. Heavy breathing may occur if a child is upset or crying. Their peak inspiratory flow rate rises, causing airflow to become more turbulent. It is the loss of laminar airflow that contributes to the softened airway collapsing. Other patients with severe TBM may have increased work of breathing at baseline during tidal breathing and will have improved work of breathing as PEEP is increased. Patients presenting with severe oxygen desaturation and decreased heart rate often respond to positive pressure bagging with $100 \%$ oxygen, with chest compressions also required on some occasions. Based on our findings, infants with perinatal HPP who have episodes of oxygen desaturation and/or changes in ventilator settings, especially increased
PEEP, should be suspected of having TBM and investigated and managed accordingly.

Data from the clinical trial program for asfotase alfa provided the opportunity to evaluate a larger population of patients with HPP who required high-pressure respiratory support. Of the 39 infants with HPP who required respiratory support, 51\% (20/39) who did not have TBM as a reported adverse event required highpressure respiratory support (PEEP $\geq 6 \mathrm{~cm} \mathrm{H}_{2} \mathrm{O}$ and/or PIP $\geq 18 \mathrm{~cm} \mathrm{H}_{2} \mathrm{O}$ ) during the studies. PEEP requirements were highly variable across the population, ranging up to $20 \mathrm{~cm} \mathrm{H}_{2} \mathrm{O}$, with $18 \%$ of patients (7/39) requiring PEEP of $\geq 8 \mathrm{~cm} \mathrm{H}_{2} \mathrm{O}$. It is possible that TBM contributed to the respiratory complications in some of these patients. It is important to note that factors other than TBM, such as chest deformity, restricted respiratory function, 
muscle weakness or sepsis, may lead to high PEEP requirements in infants with HPP. Furthermore, it is possible that infants with HPP requiring PEEP of $<6 \mathrm{~cm} \mathrm{H}_{2} \mathrm{O}$ may have TBM, although it is not likely to be clinically significant. Therefore, PEEP measurements cannot be used retrospectively to infer $\mathrm{TBM}$ or other specific respiratory symptoms or complications of HPP. However, given the frequency of high PEEP measures in the patients included in the case series, who had severe HPP and TBM, physicians should be aware that this may reflect respiratory complications including, although not limited to, TBM.

There is considerable variation in PEEP strategies employed in different pediatric intensive care units. Although bronchoscopy may inform decisions about initial respiratory requirements during quiet spontaneous respiration, these may be insufficient when a child is crying or coughing or has an intercurrent lower respiratory tract infection. Furthermore, the weaning of PEEP as symptoms improve is often empirical. Consequently, it is difficult to draw firm conclusions about either the severity of TBM or the duration of treatment solely from PEEP data. However, these data do alert us to identifying children who appear to be dependent on externally applied pressure.

Diagnosis of TBM is multifaceted [14] but should be confirmed with DLTB or flexible bronchoscopy, although bronchoscopic diagnosis of TBM is highly dependent on the conditions under which the procedure is performed. For example, if a patient is heavily sedated or paralyzed, sufficient airway collapse may not be noted if the patient does not cough or perform a Valsalva maneuver. Very severe TBM may be seen with tidal breathing, but the vigor of respiratory effort can still impact diagnosis. Earlier diagnosis and multidisciplinary approaches to care are likely to lead to improved outcomes for patients with HPP and associated TBM; consultation with a pediatric pulmonologist and a pediatric otolaryngologist is recommended for the management of such cases.

The effectiveness of asfotase alfa treatment in patients with HPP and TBM was not evaluated in the case series or the analysis of clinical trial data reported here. Decreased ventilator requirements following asfotase alfa treatment are in line with previously reported results in a case study of respiratory mechanics in an infant with perinatal HPP [9]. However, it would be difficult to determine whether any improvements in TBM were directly attributable to the promotion of skeletal mineralization by asfotase alfa or to gradual improvements in airway lumen and cartilage rigidity that may have occurred naturally with age [15]. In the latter case, the increased survival associated with asfotase alfa likely provided benefit in allowing time for the airways to mature.

This report does not evaluate adjustments in asfotase alfa dosing required to manage TBM and high respiratory support requirements in patients with perinatal
HPP. All five infants included in the case series were, at times, treated with doses higher than the standard asfotase alfa dose of $6 \mathrm{mg} / \mathrm{kg} /$ week (range: $9-15 \mathrm{mg} / \mathrm{kg} /$ week, on the basis of skeletal mineralization and growth), and the dosage was escalated in response to high ventilatory requirements. It is not possible to determine whether dose escalation contributed to improvements in TBM. Therefore, all patients with similar clinical characteristics should be managed on the standard dose of asfotase alfa, and any plan to increase the dose should be discussed with medical experts worldwide who have experience managing perinatal HPP, especially in the face of respiratory failure.

\section{Conclusion}

The findings of the current study show that TBM may be a more common comorbidity of HPP than previously thought and is probably an under-recognized contributing factor in respiratory failure in infants with HPP. It is important to screen for potential TBM in infants with HPP presenting with persistent respiratory complications (including increased PEEP requirements, oxygen desaturation events or repeated failed extubations), by using DLTB or flexible bronchoscopy at an early stage, and to initiate appropriate management strategies and treatment, as assessed by a specialist clinical team, to ensure the best prognosis.

\section{Supplementary information}

Supplementary information accompanies this paper at https://doi.org/10 1186/s13023-020-01483-9.

\section{Additional file 1.}

Additional file 2: Supplemental table 1. Infants included in the clinical trials for asfotase alfa who required high-pressure respiratory support.

\section{Abbreviations \\ CPAP: Continuous positive airway pressure; DLTB: Direct laryngotracheobronchoscopy; HPP: Hypophosphatasia; \\ PEA: Phosphoethanolamine; PEEP: Positive end-expiratory pressure; PIP: Peak inspiratory pressure; PLP: Pyridoxal-5-phosphate; PPi: Inorganic \\ pyrophosphate; TBM: Tracheobronchomalacia; TNSALP: Tissue non-specific isoenzyme of alkaline phosphatase}

\section{Acknowledgements}

The authors wish to thank Colin Glen of Oxford PharmaGenesis for medical writing support.

\section{Authors' contributions}

$\mathrm{RP}$ and HS were among the physicians responsible for the clinical care and management of the patients included in the case series described, and for supervising the collection of clinical data, and were investigators in the clinical trials of asfotase alfa that provide data analyzed for this report; they drafted the initial manuscript, and reviewed and revised the manuscript. RY and MZM were among the physicians responsible for the clinical care and management of the patients included in the case series described, and for supervising the collection of clinical data; they drafted the initial manuscript, and reviewed and revised the manuscript. DB, GM, EC, JN, CM, ON and SW were among the physicians responsible for the clinical care and management of the patients included in the case series described, and for the recording of clinical data; they critically reviewed the manuscript for 
important intellectual content. CN collected data, carried out initial analyses relating to the case series described, and reviewed and revised the manuscript. SZ conducted the analyses of data from the clinical trials of asfotase alfa that are reported, and reviewed and revised the manuscript. All authors read and approved the final manuscript.

\section{Funding}

This study was sponsored by Alexion Pharmaceuticals, Inc. (Boston, MA, USA). Editorial and writing support was provided by Colin Glen of Oxford PharmaGenesis, Oxford, UK, and funded by Alexion Pharmaceuticals, Inc.

\section{Availability of data and materials}

Qualified academic investigators may request participant-level, de-identified clinical data and supporting documents (statistical analysis plan and protocol) pertaining to this study. Further details regarding data availability, instructions for requesting information, and the data disclosure policy will be available on the Alexion.com website (http://alexion.com/researchdevelopment).

\section{Ethics approval and consent to participate}

Data from three clinical trials were analyzed: Safety and Efficacy Study of Asfotase Alfa in Severely Affected Infants With Hypophosphatasia, NCT00744042; Extension Study of Asfotase Alfa in Infants and Young Children With Hypophosphatasia, NCT01205152; Open-Label Study of Asfotase Alfa in Infants and Children $\leq 5$ Years of Age With Hypophosphatasia, NCT01176266. Site-specific approvals were granted by appropriate authorities.

\section{Consent for publication}

With two exceptions, consent for publication of patients' data was obtained at their enrollment in the clinical trials program for asfotase alfa. Consent for publication of data for the two other patients, who were not included in the clinical trials of asfotase alfa but are included in the reported case series, was provided separately to RP.

\section{Competing interests}

$\mathrm{RP}, \mathrm{HS}$ and RY are members of the Advisory Board for Alexion Pharmaceuticals, Inc. RP and HS are members of the Speakers Bureau for Alexion Pharmaceuticals, Inc. RP, HS and MZM participated as investigators in the clinical trial program for asfotase alfa, which was sponsored by Alexion Pharmaceuticals, Inc. RP, HS, RY and MZM have received honoraria from Alexion Pharmaceuticals, Inc. The other authors have no financial relationships relevant to this article to disclose.

\section{Author details}

'Department of Paediatric Endocrinology, Royal Manchester Children's Hospital and Faculty of Biology, Medicine and Health, University of Manchester, Manchester, UK. ${ }^{2}$ McMaster University, Hamilton, ON, Canada. ${ }^{3}$ Cincinnati Children's Hospital Medical Center and University of Cincinnati College of Medicine, Cincinnati, OH, USA. ${ }^{4}$ Great Ormond Street Hospital, London, UK. ${ }^{5}$ University of Manchester, Manchester, UK. ${ }^{6}$ Covance, Inc., Princeton, NJ, USA.

Received: 4 March 2020 Accepted: 26 July 2020

Published online: 06 August 2020

\section{References}

1. Whyte MP. Hypophosphatasia: an overview for 2017. Bone. 2017;102:15-25.

2. Whyte MP. Hypophosphatasia. In: Thakker RV, Whyte MP, Eisman JA, Igarashi T, editors. Genetics of bone biology and skeletal disease. London: Academic; 2013. p. 337-60

3. Whyte MP, Leung E, Wilcox WR, Liese J, Argente J, Martos-Moreno GA, et al. Natural history of perinatal and infantile hypophosphatasia: a retrospective study. J Pediatr. 2019;209:116-24.

4. Whyte MP, Rockman-Greenberg C, Ozono K, Riese R, Moseley S, Melian A, et al. Asfotase alfa treatment improves survival for perinatal and infantile hypophosphatasia. J Clin Endocrinol Metab. 2016;101(1):334-42.

5. Leung EC, Mhanni AA, Reed M, Whyte MP, Landy H, Greenberg CR. Outcome of perinatal hypophosphatasia in Manitoba mennonites: a retrospective cohort analysis. JIMD Rep. 2013;11:73-8.
6. Whyte MP, Greenberg CR, Salman NJ, Bober MB, McAlister WH, Wenkert D et al. Enzyme-replacement therapy in life-threatening hypophosphatasia. N Engl J Med. 2012;366(10):904-13.

7. Taketani T, Oyama C, Oda Y, Murphy L. Hypophosphatasia. In: Oohashi T, Tsukahara H, Ramirez F, Barber C, Otsuka F, editors. Human pathobiochemistry. Singapore: Springer; 2019. p. 91-100.

8. Bishop N. Clinical management of hypophosphatasia. Clin Cases Miner Bone Metab. 2015;12(2):170-3.

9. Rodriguez E, Bober MB, Davey L, Zamora A, Li Puma AB, Chidekel A, et al. Respiratory mechanics in an infant with perinatal lethal hypophosphatasia treated with human recombinant enzyme replacement therapy. Pediatr Pulmonol. 2012;47(9):917-22.

10. Morrison RJ, Hollister SJ, Niedner MF, Mahani MG, Park AH, Mehta DK, et al. Mitigation of tracheobronchomalacia with 3D-printed personalized medical devices in pediatric patients. Sci Transl Med. 2015;7(285):285ra64.

11. Whyte MP, Simmons JH, Moseley S, Fujita KP, Bishop N, Salman NJ, et al. Asfotase alfa for infants and young children with hypophosphatasia: 7 year outcomes of a single-arm, open-label, phase 2 extension trial. Lancet Diabetes Endocrinol. 2019;7(2):93-105.

12. Hancarova M, Krepelova A, Puchmajerova A, Soucek O, Prchalova D, Sumnik Z, et al. Hypophosphatasia due to uniparental disomy. Bone. 2015;81:765-6.

13. Mornet $\mathrm{E}$. The tissue nonspecific alkaline phosphatase gene mutations database. Available at: http://www.sesep.uvsq.fr/03_hypo_mutations.php. Accessed 2 Feb 2019.

14. Carden KA, Boiselle PM, Waltz DA, Ernst A. Tracheomalacia and tracheobronchomalacia in children and adults: an in-depth review. Chest. 2005;127(3):984-1005.

15. Murgu SD, Colt HG. Tracheobronchomalacia and excessive dynamic airway collapse. Respirology. 2006;11(4):388-406.

\section{Publisher's Note}

Springer Nature remains neutral with regard to jurisdictional claims in published maps and institutional affiliations.

\section{Ready to submit your research? Choose BMC and benefit from:}

- fast, convenient online submission

- thorough peer review by experienced researchers in your field

- rapid publication on acceptance

- support for research data, including large and complex data types

- gold Open Access which fosters wider collaboration and increased citations

- maximum visibility for your research: over $100 \mathrm{M}$ website views per year

At BMC, research is always in progress.

Learn more biomedcentral.com/submissions 